\title{
The Apparent Influence of Atmospheric Oxygen Concentration on Nitrogenase Activity and Slime Production in Klebsiella pneumoniae Grown on a Solid Medium
}

\author{
By JOHN WILCOCKSON \\ Fachbereich Biologie, Botanisches Institut der Universität, \\ 355 Marburg an der Lahn, West Germany
}

(Received 6 December 1976; revised I4 February 1977)

\begin{abstract}
Klebsiella pneumoniae strains KI I and M5a I which differ greatly in their ability to produce slime had similar ratios of nitrogenase activity when grown on agar under atmospheres of nitrogen, air or oxygen. With both strains, the rate of acetylene reduction was not significantly different when measured under air compared to nitrogen but was decreased under oxygen, which also restricted growth. Strain K I I, the more slimy of the two strains produced more slime, as measured viscometrically, when the atmosphere above the agar contained a greater proportion of oxygen up to $50 \% \mathrm{O}_{2}$. Strain M5a I gave no detectable response to increased oxygen concentration other than decreased growth and nitrogenase activity under high oxygen concentration. Despite the superficial correlation between enhanced slime production and resistance to the potentially damaging effects of oxygen on nitrogenase in air-grown nitrogen-fixing Klebsiella, slime probably contributes only marginally to that resistance.
\end{abstract}

\section{INTRODUCTION}

There is little direct evidence that slime produced by free-living aerobic and facultative anaerobic diazotrophic micro-organisms plays a beneficial role in their nitrogen-fixing activities. There are, however, a number of often quoted correlations and some circumstantial evidence.

Derxia gummosa, inoculated on a nitrogen-free agar surface, gave two colony types (Jensen et al., 1960). Only the massive, yellow and gummy colonies that occurred relatively infrequently contained nitrogen-fixing organisms; the thin white colonies did not. The proportion of the massive colonies increased if some combined nitrogen source was included in the medium (Tchan \& Jensen, 1963) or if the oxygen tension above the agar was decreased (Hill, 197I).

Colony dimorphism has also been noted with Klebsiella pneumoniae (Hill, 1975). Of the colonies growing in air on agar containing $200 \mu \mathrm{g}$ Casamino acids $\mathrm{ml}^{\mathbf{1}}$, only the infrequently occurring, large, yellow colonies were able to reduce acetylene. Possibly the large colonies developed in sparsely inoculated areas of the plates because there sufficient fixed nitrogen could diffuse to the organisms for good growth to occur. The oxygen consumption of the colony then decreased the local oxygen tension sufficiently to permit nitrogen fixation and hence further growth into a massive colony. The importance of a fixed nitrogen source for nitrogen fixation under air is clear from the work of Klucas (1972). A Klebsiella strain which would not grow in an aerated liquid culture containing no combined nitrogen grew and reduced acetylene if the medium was supplemented with a little yeast extract. Wilcockson \& Werner (1976), using Klebsiella grown on an agar medium containing 5 mmnitrate, showed that only thin young layers of organisms had their nitrogenase activity 
inhibited by normal atmospheric oxygen concentration. Nitrogenase activity in thick 'mature' layers of organisms was remarkably resistant to oxygen and, in general, the extent of acid production by a particular strain and the buffering capacity of the medium were more important factors in limiting activity.

The role of respiration in the protection of nitrogenase is probably important (see Dalton \& Postgate, 1969; Postgate, 1971; Hill, Drozd \& Postgate, 1972). Theoretically both the rate of oxygen consumption and the severity of the diffusion barrier will determine the concentration of oxygen to which the nitrogenase will be exposed; the question is what is the relative significance of these two factors. Since slime consists almost entirely of water, it is difficult on theoretical grounds to see how it could present a barrier to the diffusion of dissolved gases more severe than a similar thickness of water. The transport of oxygen to sensitive sites within a colony could be modified by the presence of slime through an effect on the solution rate of the gas or even on the convection of liquid containing dissolved oxygen. Both of these possibilities have to be considered although they will be very much more important in liquid cultures especially if agitated.

In the present paper, data are presented which suggest that, despite a clear increase in slime production at increased oxygen concentrations, the contribution which this oxygeninduced increment in slime or the bulk of slime which is present under low oxygen tension makes towards protecting the nitrogenase is very slight.

\section{METHODS}

Growth of the organisms and measurement of nitrogenase activity. The strains used in this work were Klebsiella pneumoniae M5aI, an indole producer of the 'oxytocum' group, obtained from Professor J. R. Postgate, and strain KII, a typical K. pneumoniae, which now shows some trivial differences from the original isolate of marine origin (called M-4, Werner, Evans \& Seidler, 1974). Both strains were maintained on medium M20e (Werner, Wilcockson \& Zimmermann, 1975) solidified with agar, Organisms for inoculation of experimental vials were taken from an overnight culture grown in $100 \mathrm{ml}$ medium M2oe in a $300 \mathrm{ml}$ Erlenmeyer flask, sealed with a porous plug, at $28^{\circ} \mathrm{C}$ on a rotary shaker; $0.05 \mathrm{ml}$ was inoculated on the surface of $2 \mathrm{ml}$ agar medium. This medium was basically M2oe but contained $3 \%(\mathrm{w} / \mathrm{v})$ sucrose and $0.125 \mathrm{M}-\mathrm{Tris} / \mathrm{HCl}$

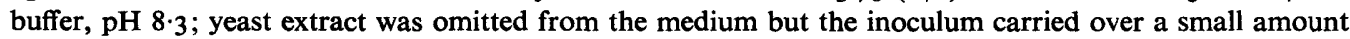
from the $2 \cdot 0 \mathrm{~g}^{-1}$ present in the liquid M2oe. The glass vial which contained the medium had a volume of $5.5 \mathrm{ml}$ when sealed with a metal screw-cap for sterilization of the medium by autoclaving. After inoculation, the vials (without caps) were each placed in a wide-mouthed glass bottle (a marmalade jar) closed by a gastight screw-cap drilled with a central hole of about $\mathrm{I} \mathrm{cm}$ diameter. After flushing with the desired gas mixture for about $30 \mathrm{~s}$ the hole was sealed by a tight-fitting rubber stopper with a membrane for the addition or removal of gas by syringe and needle; $30 \mathrm{~s}$ was adequate for the flushing operation since acetylene, when present initially, could not be detected by gas chromatography in samples taken from the jar after flushing. No precautions against contamination of the agar surfaces during flushing were considered necessary since the inoculation by these fast-growing organisms is massive (about $10^{8}$ organisms $\mathrm{cm}^{-2}$ ). In addition, plating out of the organisms of each experiment never showed contamination by an organism exhibiting different colony morphology. The jars with the upright vials inside were incubated at $28{ }^{\circ} \mathrm{C}$ for $48 \mathrm{~h}$ before $36 \mathrm{ml}$ of the gas was removed ( $10 \%$ of the total volume) and replaced by $36 \mathrm{ml}$ acetylene. After a further $24 \mathrm{~h}$ incubation $0.5 \mathrm{ml}$ samples of the gas were removed with a $\mathrm{I} \mathrm{ml}$ syringe and the ethylene content was determined by gas chromatography as described by Wilcockson \& Werner (1976). In other 'gas switch' experiments, the gas atmosphere was changed at $48 \mathrm{~h}$ for another of a different composition and, after $2 \mathrm{~h}$ equilibration, this new atmosphere was made to $10 \%$ acetylene. The jars were incubated for a further $2 \mathrm{~h}$ before samples were removed for measurement of the ethylene content.

Measurement of protein concentration and culture viscosity. Two $\mathrm{ml}$ water was added to each vial, the bacteria were gently scraped from the agar surface under the water and then the vial was vigorously shaken. The suspension was drawn in and out of a syringe fitted with a wide-gauge needle several times before being filtered through a nylon gauze with a pore size of about Io $\mu \mathrm{m}$ (Perlon Gaze, Vereinigte Seidenwebereien, Krefeld, West Germany) to remove any agar particles. The turbidity of the suspensions pooled from three or five replicate vials was measured in an EEL nephelometer and the total protein content was estimated (Lowry et al., 195I). The approximate viscosity of a suspension was measured by timing its run out of a fine bore $0.1 \mathrm{ml}$ pipette; the times varied for different suspensions from 2.5 to $13 \mathrm{~s}$. The greatest difference between 
three readings taken on the same suspension was $0.3 \mathrm{~s}$ or less. The average of the three readings was converted into an approximate figure for viscosity by comparison with standard sucrose solutions of known viscosity (Iscotables, Instrument Specialities Company, Lincoln, Nebraska, U.S.A., 1967) run out of the same pipette.

\section{RESULTS}

Nitrogenase activities of $K$. pneumoniae M5a I and KI I were unchanged when the whole of the growth and acetylene-reducing period was under air instead of nitrogen (Table 1 ). A variation of about 15 to $20 \%$ was found between yields of bacteria recovered from replicate vials; this was probably due to differences in the inocula and in the microclimate which would influence growth. Consequently the difference in nitrogenase activity between the two strains is probably not significant. For unknown reasons the values for acetylene reduction varied between replicate vials from better than $\pm 20 \%$ for air- or nitrogen-grown organisms to $\pm 50 \%$ for growth under oxygen. The variation in protein determinations was similar for suspensions of cells grown on agar under all three gas regimes. Turbidity measurements on resuspended bacterial cultures indicated that growth was greater under air or nitrogen with M5aI than with KII, and that there was less growth of both bacterial strains under oxygen.

Suspensions of strain M5a I, despite showing better growth than KI I (except under oxygen), exhibited a far lower viscosity (Table I). Suspensions of M5a I grown under air, nitrogen or oxygen were only slightly more viscous than water using the same 'viscometer' even when the organisms were resuspended in a smaller volume. The viscosity of $K$. pneumoniae KI I was much higher: when grown under air it was more viscous than when grown under nitrogen although neither nephelometer values nor estimates of total protein suggested that there were more bacteria present in the case of air-grown cells. When grown under oxygen it had an intermediate viscosity (Table I). However, growth under oxygen is clearly less than under the other two gas regimes and the reason for this result is not obvious.

Because there was a greater variation in protein estimations between replicate vials than in replicate measurements on the same suspension, there could be a small but undetected difference in the amount of material present in strain KI I grown under air or under nitrogen and this could, because of the acute concentration dependence of viscosity, account for the different viscosity measurements. When growth, measured by total protein content or by nephelometry, was plotted against the viscosity determinations, suspensions of air- or nitrogen-grown organisms had quite separate distributions of points (Fig. I $a, b$ ). Although considerable variations in the amount of bacterial protein or nephelometer values were obtained and equal or sometimes overlapping viscosity times were recorded, organisms grown under air clearly produced more of some material contributing to the total viscosity of the suspensions than did the nitrogen-grown organisms.

When organisms were grown under atmospheres ranging in composition from $100 \%$ $\mathrm{N}_{2}$ to $100 \% \mathrm{O}_{2}$, the complications caused by the concentration dependence of viscosity became evident (Table 2). The suspension of organisms grown under nitrogen was more viscous than that of bacteria grown under oxygen $(7 \cdot 87$ and $7 \cdot 10 \mathrm{~s}$ meniscus fall times respectively). However, the total protein of organisms grown under the oxygen atmosphere was almost half that of those grown anaerobically. All the values for protein content, but not the viscosities, of bacteria grown under atmospheres of nitrogen and oxygen of a range of compositions between the two extremes, were intermediate. Viscosities of solutions of sucrose matching the viscosities of the bacterial suspensions were approximately proportional to the fourth power of the concentration. If a fourth power proportionality of viscosity to bacterial concentration (i.e. protein) is assumed for the suspensions of KI I the values for $V$ (mg protein $)^{-4}$ are not the same but increase with the oxygen content of the atmosphere up to about $50 \% \mathrm{O}_{2}$ whereafter they remain approximately constant (Table 2).

To see if the increase in slime production which occurs when KII is grown under air 
Table I. Growth, nitrogenase activity and suspension viscosity in Klebsiella strains M5 I and $\mathrm{KI}$ I grown under nitrogen, air and oxygen

\begin{tabular}{|c|c|c|c|c|c|c|}
\hline & \multicolumn{3}{|c|}{$\begin{array}{l}K . \text { pneumoniae M5a I } \\
\text { Gas phase above culture } \\
\text { during growth }\end{array}$} & \multicolumn{3}{|c|}{$\begin{array}{c}K \text {. pneumoniae KI I } \\
\text { Gas phase above culture } \\
\text { during growth }\end{array}$} \\
\hline & $\mathbf{N}_{2}$ & Air & $\mathrm{O}_{2}$ & $\mathbf{N}_{2}$ & Air & $\mathrm{O}_{2}$ \\
\hline $\begin{array}{l}\text { Nitrogenase activity }\left(\mathrm{nmol} \mathrm{C}_{2} \mathrm{H}_{4}\right. \\
\left.\text { produced } \mathrm{min}^{-1} \text { vial }^{-1}\right)\end{array}$ & $9 \cdot 98^{*}$ & I I $97^{*}$ & 3.64 & $6 \cdot 63^{*}$ & $7.07^{*}$ & $2 \cdot 70$ \\
\hline Total bacterial protein $\left(\mathrm{mg} \mathrm{vial}^{-1}\right)$ & $1 \cdot 32$ & $I \cdot 24$ & $0 \cdot 74$ & $1 \cdot 13$ & $1 \cdot 18$ & 0.90 \\
\hline $\begin{array}{l}\text { Bacterial growth (nephelometer } \\
\text { units) }\end{array}$ & $143 \cdot 7$ & $15 I \cdot 3$ & $100 \cdot 7$ & $118 \cdot 0$ & $115 \cdot 7$ & $97 \cdot 4$ \\
\hline Viscosity (meniscus fall time, $s$ ) & $2 \cdot 28$ & $2 \cdot 30$ & $2 \cdot 27$ & $6 \cdot 19$ & $8 \cdot 88$ & $7 \cdot 01$ \\
\hline
\end{tabular}

* The difference between the figures for nitrogenase activity under air and nitrogen for the two strains arises because on this medium (buffered with $0 \cdot 125 \mathrm{M}$-Tris $/ \mathrm{HCl}, \mathrm{pH} \mathrm{8.3)} \mathrm{the} \mathrm{maximum} \mathrm{rates} \mathrm{are} \mathrm{not} \mathrm{reached.}$ These bacteria lower the $\mathrm{pH}$ at the surface of the agar and this decreases activity; $\mathrm{KI}$ I is a more potent acid producer than M5aI and this results in a lower activity (Wilcockson \& Werner, 1976).
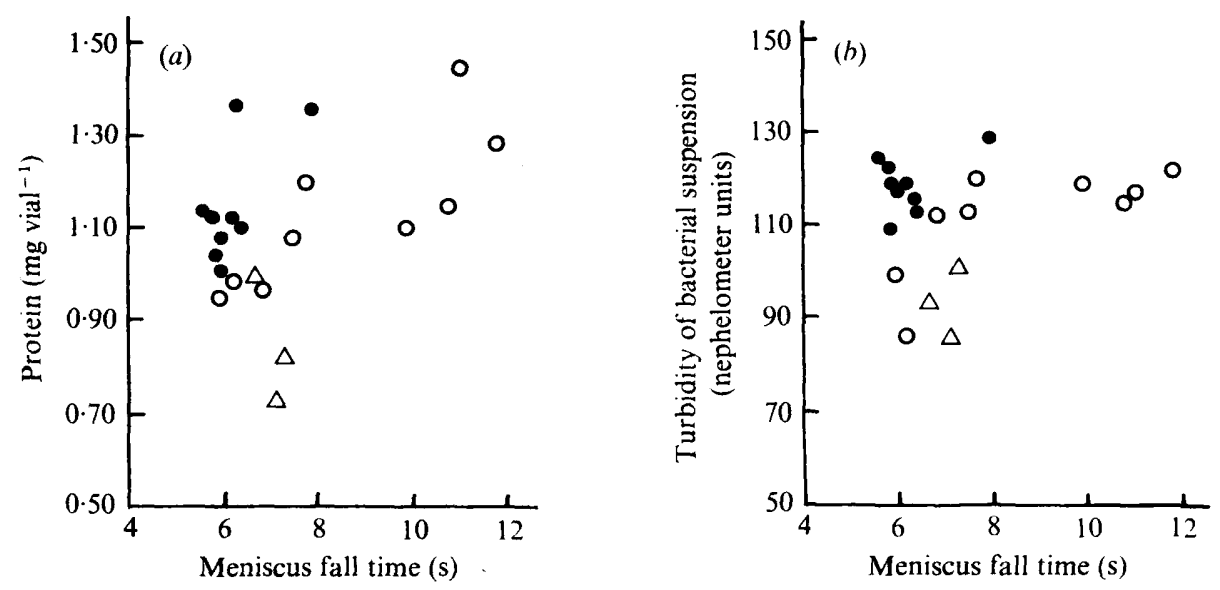

Fig. I. Effect of variation in the growth of Klebsiella pneumoniae KI I under atmospheres of air, nitrogen or oxygen on the viscosity of the suspended organisms. Suspensions of bacteria grown under air $(O)$, nitrogen $(O)$ or oxygen $(\triangle)$ from three replicate vials were pooled and the average values for protein concentration $(a)$ and turbidity $(b)$ were plotted against the corresponding meniscus fall times. The data for nitrogen- and air-grown organisms are from three separate experiments; those for oxygen-grown organisms are from one experiment.

Vials were incubated for $72 \mathrm{~h}$ under the appropriate atmosphere; during the last $24 \mathrm{~h}$ this included $10 \%$ acetylene. The scatter of the points results from variation in growth of the bacteria and variation in the measurement of this by the Lowry method or by nephelometry. Horizontal scatter arises from differences in the viscosity of the suspensions. Variation in the measurement of 'viscosity' as meniscus fall time does not contribute significantly to the horizontal scatter.

instead of nitrogen contributes to the oxygen tolerance of nitrogenase in air-grown organisms, organisms were grown under nitrogen and then switched to air, and nitrogenase activity was assessed after $2 \mathrm{~h}$ equilibration. No significant difference was observed in the rate of acetylene reduction compared with that for organisms grown for the whole period under air or nitrogen (Table 3). The reciprocal experiment, in which air-grown organisms were switched to nitrogen, also did not affect the rate of acetylene reduction. Nitrogengrown organisms which did not have their air-induced increase in slime production, showed no special sensitivity even when switched into an oxygen atmosphere for equilibration and assessment of nitrogenase activity. 
Table 2. Effect of oxygen concentration on growth, nitrogenase activity and viscosity of suspended organisms of Klebsiella pneumoniae $\mathrm{KI} I$

Data were obtained from three pooled replicate vials.

\begin{tabular}{|c|c|c|c|c|c|c|}
\hline $\begin{array}{l}\text { Oxygen concn } \\
\left.\%, v / v \text {, in } N_{2}\right)\end{array}$ & $\begin{array}{c}\text { Nitro- } \\
\text { genase } \\
\text { activity } \\
\text { (nmol } \mathrm{C}_{2} \mathrm{H}_{4} \\
\text { produced } \\
\text { min }^{-1} \text { vial }^{-1} \text { ) }\end{array}$ & $\begin{array}{c}\text { Total } \\
\text { protein } \\
\text { after } \\
72 \mathrm{~h} \\
\left(\mathrm{mg} \mathrm{vial}^{-1}\right)\end{array}$ & $\begin{array}{c}\text { Viscosity } \\
\text { (meniscus } \\
\text { fall time, s) }\end{array}$ & $\begin{array}{l}\text { Sucrose } \\
\text { equivalent* } \\
(\%, w / v)\end{array}$ & $\begin{array}{l}\text { Viscosity, } V \\
\text { (cP) }\end{array}$ & $\begin{array}{c}V(\mathrm{mg} \\
\text { protein })^{-4}\end{array}$ \\
\hline 0 & $6 \cdot 2 \mathrm{I}$ & $1 \cdot 36$ & $7 \cdot 87$ & $42 \cdot 25$ & $7 \cdot 35$ & $2 \cdot 17$ \\
\hline 5 & $7 \cdot 23$ & $I \cdot 22$ & 9.90 & 47.00 & I I 35 & $5 \cdot 11$ \\
\hline 10 & $6 \cdot 14$ & $I \cdot I I I$ & $9 \cdot 63$ & $46 \cdot 50$ & 10.85 & $7 \cdot 23$ \\
\hline 20 & $6 \cdot 13$ & $I \cdot 18$ & II 70 & $50 \cdot 00$ & 15.40 & 7.91 \\
\hline 50 & 5.59 & 0.93 & I I 40 & $49 \cdot 50$ & 14.65 & 19.43 \\
\hline 75 & $4 \cdot 26$ & 1.05 & 13.00 & $5 I \cdot 75$ & 18.90 & $15.8 \mathrm{I}$ \\
\hline 100 & $\mathrm{I} \cdot 58$ & 0.75 & $7 \cdot 10$ & $39 \cdot 75$ & 6.05 & 18.89 \\
\hline
\end{tabular}

* Concentration of sucrose solution having a meniscus fall time equivalent to that of the KI I suspension.

Table 3. Effect on Klebsiella pneumoniae $\mathrm{KI}$ I of switching air-or nitrogen-grown organisms into another atmosphere for assessment of nitrogenase activity

Organisms were grown in an atmosphere of air or nitrogen for the first $48 \mathrm{~h}$ and were then switched to nitrogen, air or oxygen for the last $4 \mathrm{~h}$ of incubation $(2 \mathrm{~h}$ for equilibration and $2 \mathrm{~h}$ for acetylene reduction).

\begin{tabular}{|c|c|c|c|c|}
\hline & \multirow{2}{*}{$\begin{array}{l}\text { Gas phase for } \\
\text { first } 48 \mathrm{~h}\end{array}$} & \multicolumn{3}{|c|}{ Gas phase for last $4 \mathrm{~h}$} \\
\hline & & $\mathbf{N}_{2}$ & Air & $\mathrm{O}_{2}$ \\
\hline $\begin{array}{l}\text { Nitrogenase activity } \\
\left(\mathrm{nmol} \mathrm{C}_{2} \mathrm{H}_{4} \text { produced } \min ^{-1} \text { vial }^{-1}\right)\end{array}$ & $\underset{\mathrm{N}_{2}}{\mathrm{Air}}$ & $\begin{array}{l}5 \cdot 81 \\
5 \cdot 54\end{array}$ & $\begin{array}{l}7 \cdot 15 \\
6 \cdot 72\end{array}$ & $\begin{array}{l}4 \cdot 15 \\
3 \cdot 32\end{array}$ \\
\hline Total bacterial protein (mg vial $\left.{ }^{-1}\right)$ & $\underset{\mathbf{N}_{2}}{\operatorname{Air}}$ & $\begin{array}{l}I \cdot 32 \\
I \cdot I 3\end{array}$ & $\begin{array}{l}1.05 \\
1.06\end{array}$ & $\begin{array}{l}1 \cdot 09 \\
I \cdot 04\end{array}$ \\
\hline Turbidity (nephelometer units) & $\underset{\mathrm{N}_{2}}{\mathrm{Air}}$ & $\begin{array}{l}\text { I } 18 \cdot 5 \\
124 \cdot 0\end{array}$ & $\begin{array}{l}107 \cdot 0 \\
11 I \cdot 0\end{array}$ & $\begin{array}{l}\text { II } 6 \cdot 0 \\
\text { I } 18 \cdot 0\end{array}$ \\
\hline Viscosity (meniscus fall time, $\mathrm{s}$ ) & $\underset{\mathrm{N}_{2}}{\mathrm{Air}}$ & $\begin{array}{l}9.25 \\
5.65\end{array}$ & $\begin{array}{l}8 \cdot 32 \\
6 \cdot 10\end{array}$ & $\begin{array}{l}8.65 \\
5.95\end{array}$ \\
\hline
\end{tabular}

The relatively short time for equilibration $(2 \mathrm{~h})$ and measurement of acetylene reduction was chosen in case a $24 \mathrm{~h}$ incubation of organisms, switched from a nitrogen atmosphere to air or oxygen, resulted in enhanced slime production thereby complicating the interpretation of the results. The viscosities (Table 3 ) indicate that switching nitrogen-grown organisms to one of the other gases for $4 \mathrm{~h}$ did not increase the viscosity. Similarly, for airgrown bacteria, a switch to a nitrogen atmosphere did not decrease the viscosity.

\section{DISCUSSION}

Klebsiella pneumoniae strain $\mathrm{KI}$, which is more slimy than strain M5a I even when growing under nitrogen, exhibits an increase in slime production when oxygen is present in the atmosphere above organisms grown on agar. The evidence is strongly against this being due to any slight and unseen difference in the growth of the bacteria under the two regimes. Wilcockson \& Werner (1976) showed that the protein content of strain KI I grown under air contributed only about $20 \%$ of the dry weight of these cells whereas this figure could rise to almost $33 \%$ for bacteria grown on the same medium but under nitrogen. In contrast, in strain M5a I, protein contributes about $75 \%$ of the dry weight in liquid culture (Tubb \& Postgate, 1973). Since 50 to $60 \%$ of the dry weight of this organism growing on agar under air or nitrogen was protein, some of the extracellular slime probably becomes detached 
and dissolves in the medium in liquid cultures (unpublished results). No response of this strain to oxygen manifesting itself as increased viscosity could be found, despite the high sensitivity of the meniscus fall technique. Since suspensions of strain M5aI, which, except under oxygen, always showed more growth than KI I, have meniscus fall times scarcely different from water, any subtle change in morphology of strain KII grown under the various gas regimes is not likely to account for the greater viscosities of suspensions of this strain. No gross changes in morphology of the organisms from suspensions of air- or nitrogengrown KII were seen microscopically and no evidence that air-grown KII was more susceptible to lysis in the resuspending procedure was found.

Slime production may be increased by a nitrogen or phosphate limitation (Duguid \& Wilkinson, 196I). Although the organisms growing on an agar substratum are clearly not homogeneous and certain locations inside the mass might be anaerobic, oxygen-limited or have nutritional limitation, it is unlikely that KII in this system has generalized nitrogen limitation. Indeed adding even small amounts of ammonium ion to the medium decreases acetylene-reducing activity but leads to only a small 'step up' in growth (Wilcockson \& Werner, 1976) which, in liquid-grown $K$. pneumoniae, is characteristic of repression (Tubb \& Postgate, I973). The medium contained only I mM-phosphate and this could be limiting. However, when the medium was buffered with phosphate buffer instead of $\mathrm{Tris} / \mathrm{HCl}$, the observed rates of acetylene reduction were only higher if its buffer capacity was higher than

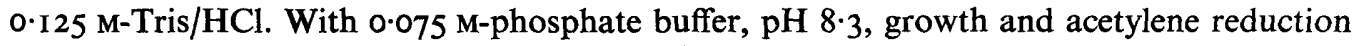
by $\mathrm{KII}$ were similar to those in $0.125 \mathrm{M}$-Tris/ $\mathrm{HCl}$. The buffering potential of these buffer systems is similar (J. Wilcockson \& D. Werner, unpublished data). Tris is not readily utilizable by strain KI I as a nitrogen source since only weak growth occurred on the medium containing no nitrate and in an air atmosphere, especially if the organisms from the liquid culture forming the inoculum were thoroughly washed free of yeast extract.

Though it is tempting to interpret the oxygen-induced increase in slime production shown by strain KI I as an environmental response which permits nitrogenase to be synthesized or function more effectively in air, two points detract from such a conclusion. Firstly, under all conditions tested Klebsiella pneumoniae M5aI and KII have very different levels of slime production and yet both suffer no loss of activity in terms of acetylene-reducing activity when grown on agar under air as opposed to nitrogen. Secondly, the nitrogenase of strain KI I grown under nitrogen was not especially sensitive to oxygen and seemed to be no more sensitive to oxygen than the nitrogenase of air-grown organisms which have more slime.

Comparisons of the viscosity of suspensions of organisms grown on agar under a range of $\mathrm{O}_{2} / \mathrm{N}_{2}$ mixtures [as $V$ (mg protein) ${ }^{-4}$, see Table 2] are interpreted as supporting a progressive effect of oxygen on slime production. Klebsiella pneumoniae appears to manufacture more slime relative to protein when grown on agar surfaces under atmospheres containing increasing proportions of oxygen up to about $50 \% \mathrm{O}_{2}$ after which it remains approximately constant.

I am most grateful to Professor W. Mannheim of the Hygiene Institute of this University for advice and formal identification of the bacterial strains used in this work. The project was made possible by a grant from the Deutsche Forschungsgemeinschaft (DFG) through Sonderforschungsbereich (SFB) I03 to Professor D. Werner of the Botanical Institute of the University whose advice and encouragement it is also a pleasure to acknowledge.

\section{REFERENCES}

Dalton, H. \& Postgate, J. R. (I969). Effect of oxygen on growth of Azotobacter chroococcum in batch and continuous culture. Journal of General Microbiology 54, 463-473.
Duguid, J. P. \& Wilkinson, J. F. (196I). Environmentally induced changes in bacterial morphology. Symposia of the Society for General Microbiology Ir, 69-99. 
HILL, S. (I97I). Influence of oxygen concentration on the colony type of Derxia gummosa grown on nitrogen-free media. Journal of General Microbiology 67, 77-83.

Hill, S. (1975). Acetylene reduction by Klebsiella pneumoniae in air related to colony dimorphism on low fixed nitrogen. Journal of General Microbiology 91, 207-209.

Hill, S., Drozd, J. W. \& Postgate, J. R. (1972). Environmental effects on the growth of nitrogenfixing bacteria. Journal of Applied Chemistry and Biotechnology 22, 54I-558.

Jensen, H. L., Petersen, E. J., De, P. K. \& BhatTACHARYA, R. (1960). A new nitrogen-fixing bacterium: Derxia gummosa nov. gen. nov. spec. Archiv für Mikrobiologie 36, 182-195.

KLUCAS, R. (1972). Nitrogen fixation by Klebsiella grown in the presence of oxygen. Canadian Journal of Microbiology 18, I845-1850.

Lowry, O. H., Rosebrough, N. J., FARr, A. L. \& RANDALL, R. J. (195I). Protein measurement with the Folin phenol reagent. Journal of Biological Chemistry 193, 265-275.

Postgate, J. R. (197I). Relevant aspects of the physiological chemistry of nitrogen fixation. Symposia of the Society for General Microbiology 2r, 287-307.

TChan, Y. T. \& Jensen, H. L. (I963). Studies on nitrogen-fixing bacteria. VIII. Influence of $\mathrm{N}$ content of the media on the $\mathrm{N}$-fixation capacity and colony variation of Derxia gummosa Jensen et al. 1960. Proceedings of the Linnean Society of New South Wales 88, 379-385.

TubB, R. S. \& Postgate, J. R. (1973). Control of nitrogenase synthesis in Klebsiella pneumoniae. Journal of General Microbiology 79, 103-1 17.

WerNer, D., Evans, H. J. \& SeIDLER, R. J. (1974). Facultatively anaerobic nitrogen-fixing bacteria from the marine environment. Canadian Journal of Microbiology 20, 59-64.

WeRner, D., Wilcockson, J. \& ZimmermanN, E. (1975). Adsorption and selection of rhizobia with ion-exchange papers. Archives of Microbiology 105, 27-32.

Wilcockson, J. \& WeRner, D. (1976). Nitrogenase activity by Klebsiella and Rhizobium on solid substrata exposed to air. Bericht der Deutschen botanischen Gesellschaft 89, 587-607. 